\title{
Hugo Rietveld, the Person and the Method
}

Hugo Rietveld, the man the Rietveld method is named after, passed away July 2016. He was born in The Netherlands, grew up in Australia as a youth, and obtained his $\mathrm{PhD}$ at the University of Western Australia in Perth. In 1964 he returned to The Netherlands where he worked for Reactor Centrum Nederland (RCN) in Petten. It was at RCN that Hugo published a paper presenting the crystal structures from powder diffraction data of alkaline earth metal urinates (Rietveld, 1966a) where he used both X-ray and neutron diffraction for crystal structure determination. Of interest is a comment in the Experimental section of this paper regarding neutron diffraction data collection, "With the reactor operating at $20 \mathrm{MW}$ thermal power, it took 1 week to collect a set of data"! His original structure work primarily relied on resolved integrated peak intensities. However, Rietveld realized there was a need to be able to work with neutron powder diffraction data that had poorly resolved diffraction peaks, beyond existing manual deconvolution methods. Hugo Rietveld presented his ideas on including profile fitting methods as part of the crystal structure determination process using neutron diffraction data, at the IUCr Meeting held in Moscow, Russia in July 1966 (Rietveld, 1966b). In 1967, he published a short communication using $\mathrm{WO}_{3}$ as an example, in Acta Crystallographica (Rietveld, 1967). What was described was a hybrid structure method where individually resolved integrated peak intensities and data obtained from least-squares refinement of peak overlap regions of a diffraction pattern, could be combined for structure refinement. His "refined" approach of using only refined peak profiles for powder diffraction pattern fitting was published in 1969 (Rietveld, 1969a), and described in detail in RCN Report RCN-104 (Rietveld, 1969b). The programming language was ALGOL (Algorithmic Language). The beginning comment of the program code is shown in Figure 1.

It took several years for Hugo Rietveld's ALGOL refinement code to be accepted by the neutron powder diffraction community (Hewat et al., 2016), with adaption by X-ray powder diffraction users beginning around 1977 (Malmros and Thomas, 1977). Today, the method referred to as Rietveld refinement is the de facto standard for whole pattern refinement of powder diffraction data. Thousands of scientific papers have been published using the Rietveld method, and over
Figure 1. Opening comment for Hugo Rietveld's ALGOL program for structure refinement.
4200 unique diffraction data entries are published in the ICDD $^{\circledR}$ Powder Diffraction File ${ }^{\mathrm{TM}}\left(\mathrm{PDF}^{\circledR}\right)$ (ICDD, 2016) with the Rietveld quality mark. Hugo Rietveld has been recognized for his seminal work, including in 2003 where he was presented with the Barrett Award at the Denver X-ray Conference $^{\circledR}$ (Figure 2).

The powder diffraction community is indebted to Hugo Rietveld for his method of profile fitting diffraction data where today not only is it being used for structure refinement, but it is also a key analytical method for quantitative phase analysis using powder diffraction techniques. In June 2016, I had the opportunity to attend the EPDIC 15 Meeting in Bari, Italy. William David presented an outstanding lecture "Hugo Rietveld and The Method: Celebrating 50 Years of Real Crystallography”. Not only did we hear about Hugo's scientific achievements, but we also learned about Hugo as a person, family man and well-respected colleague.

Though he is no longer with us in body, he will continue to live amongst us in spirit. Thank you Hugo.

Tom Blanton

ICDD Principal Scientist

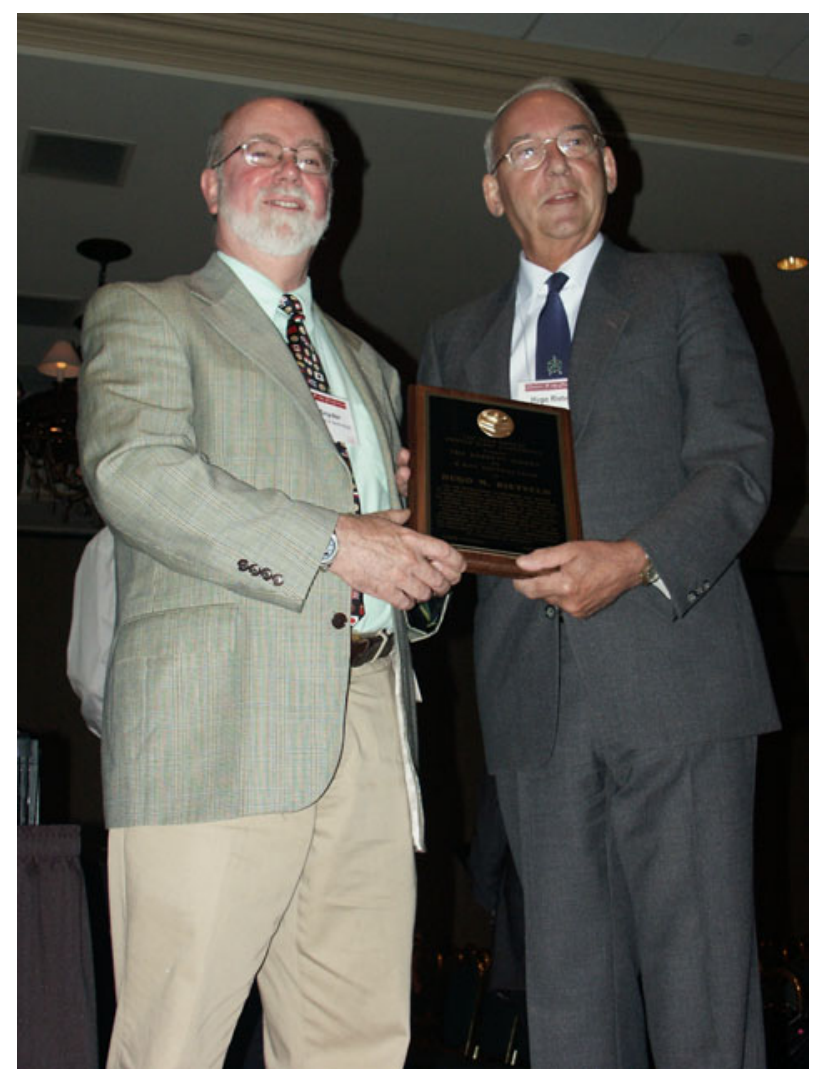

Figure 2. Presentation of the Barrett Award to Hugo Rietveld (R) by Bob Snyder (L). 
Hewat, A., David, W. I. F., and van Eijck, L. (2016). "Hugo Rietveld (19322016),” J. Appl. Crystallogr. 49, 1394-1395.

ICDD (2016). PDF-4+ 2016 (Database), edited by Dr. Soorya Kabekkodu, International Centre for Diffraction Data, Newtown Square, PA, USA.

Malmros, G. and Thomas, J. O. (1977). "Least-squares structure refinement based on profile analysis of powder film intensity data measured on an automatic densitometer," J. Appl. Crystallogr. 10, 7-11.

Rietveld, H. M. (1966a). "The crystal structure of some alkaline earth metal urinates of the type $\mathrm{M}_{3} \mathrm{UO}_{6}$," Acta Crystallogr. 20, 508-513.
Rietveld, H. M. (1966b). "A method for including the line profiles of neutron powder diffraction peaks in the determination of crystal structures (Abstract 14.7)," Acta Crystallogr. Suppl. 21, A228.

Rietveld, H. M. (1967). "Line profiles of neutron powder-diffraction peaks for structure refinement," Acta Crystallogr. 22, 151-152.

Rietveld, H. M. (1969a). "A profile refinement method for nuclear and magnetic structures," J. Appl. Crystallogr. 2, 65-71.

Rietveld, H. M. (1969b). An ALGOL program for the refinement of nuclear and magnetic structures by the profile method. Reactor Centrum Nederland, RCN-104. http://www.iaea.org/inis/collection/NCLCollection Store/_Public/46/087/46087996.pdf 